\title{
Use of therapeutic non-refractive contact lenses to improve visual outcome after repair of traumatic corneal wounds
}

This article was published in the following Dove Press journal:

Clinical Ophthalmology

28 August 2014

Number of times this article has been viewed

\section{Mohammad M Khater}

Ophthalmology Department, Tanta University Hospital, Tanta, El Gharbia Governorate, Egypt

Video abstract

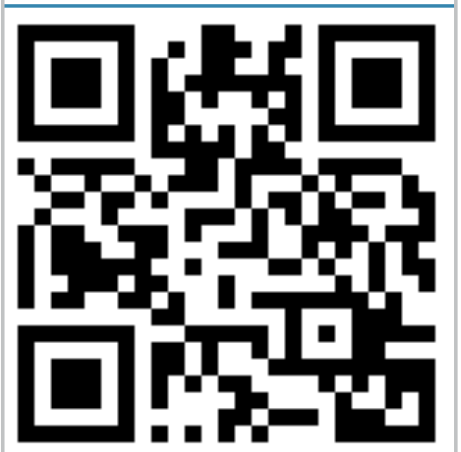

Point your SmartPhone at the code above. If you have a $Q R$ code reader the video abstract will appear. Or use: http://dvpr.es/IqbakXG

Correspondence: Mohammad M Khater Ophthalmology Department, Tanta University Hospital, Tanta, El Gharbia Governorate, Egypt

Email ophlover@yahoo.com
Background: The purpose of this study was to evaluate the effect of use of contact lenses to improve visual outcome after repair of traumatic corneal wounds.

Methods: Two groups of patients ( $\mathrm{n}=30$ each) with traumatic full thickness corneal wounds were entered into this study. All cases were caused by sharp objects such as a knife or piece of glass that produced a corneal full thickness wound without any other associated ocular injuries. One group was repaired and received medical treatment (non-contact lens group) and the other group was repaired and a soft contact lens was fitted over the cornea, then medically treated (contact lens group). Each patient was followed up until complete healing, the sutures were removed after about 6 weeks, and the patients were followed up for a further 6 weeks, for a complete follow-up period of 3 months, after which postoperative refraction, manifest refractive spherical equivalent, uncorrected visual acuity, and best-corrected visual acuity were measured and compared between the two groups.

Results: After repair and follow-up, uncorrected visual acuity $\geq 0.3$ (decimal system) was achieved in 19 cases (63\%) in the contact lens group and in only 14 cases $(47 \%)$ in the non-contact lens group $(P=0.018)$. Best-corrected visual acuity $\geq 0.6$ was achieved in 26 cases $(87 \%)$ in the contact lens group and in only 17 cases $(57 \%)$ in the control group $(P=0.012)$.

Conclusion: Soft contact lenses can be used after repair of traumatic corneal wounds to improve visual outcome.

Keywords: non-refractive contact lenses, traumatic corneal wounds, repair, visual outcome

\section{Introduction}

Traumatic rupture globe injuries are sight-threatening conditions that may end in considerable visual impairment, and even visual loss in many instances with a severe globe insult. ${ }^{1,2}$ Traumatic corneal wounds carry a hopeful and good prognosis especially if not associated with other ocular injuries and managed properly. ${ }^{3}$ Patients in many instances may present late, which delays management and carries a risk of intraocular infection, so the condition may worsen, affecting the prognosis. ${ }^{4,5}$ Management of traumatic corneal wounds is challenging and no standards are defined. ${ }^{6}$ Therapeutic contact lenses have been used in a variety of corneal disorders to help healing of recurrent epithelial erosions, corneal dystrophy, corneal ulcers, and corneal chemical injuries, and post photorefractive keratectomy. ${ }^{7}$ The present study reports on the usefulness of contact lenses in decreasing the degree of induced astigmatism and improving the visual outcome after repair of traumatic corneal wounds. 


\section{Patients and methods}

Patients included in this study attended the emergency room at the Ophthalmology Department, Tanta University Hospital, Egypt, in the period from April 2012 to March 2014. On the first visit, a detailed history was taken and a careful ophthalmological examination of both eyes (the injured eye and the sound eye) was done in order to detect any previous ocular pathology or diseases in the injured eye that would affect vision, so that these cases could be excluded from the study. All cases were suffering from different forms of traumatic full thickness corneal wounds caused by sharp objects like a knife or a piece of glass as stated by the patients during history-taking. All eyes were examined by slit-lamp and demonstrated no other ocular injuries other than the corneal wound in the anterior segment. An informed consent was obtained from all study participants. Ethics committee approval for the study was obtained.

The patients, all with traumatic full thickness corneal wounds, were divided into two groups ( $\mathrm{n}=30$ each), comprising a non-contact lens group in which all eyes were repaired without fitting a contact lens and the other a contact lens group in which a soft contact lens (Dailies ${ }^{\circledR}$, CIBA Vision Inc., Des Plaines, IL, USA) with (0) power was fitted over the cornea after repair. All patients underwent surgical repair under general anesthesia using nylon 10/0 sutures (Ethilon ${ }^{\circledR}$, Ethicon Inc., Cincinnati, OH, USA). In eleven cases (five contact lens and six non-contact lens), the prolapsed iris could not be repositioned during repair, so was excised. After repair with corneal sutures, all patients were treated medically with a broad-spectrum antibiotic (moxifloxacin; Vigamox $^{\circledR}$, Alcon Inc., Fort Worth, TX, USA), prednisolone acetate (Pred-Forte ${ }^{\circledR}$, Allergan Inc., Irvine, CA, USA) and atropine sulfate (Isopto ${ }^{\circledR}$ atropine, Alcon Inc.). After the primary repair was done, all patients in both groups were admitted for 5 days and kept under observation. During admission, ocular ultrasonography was done routinely for every patient to assess the posterior segment and exclude its involvement. In the contact lens group, the soft contact lens was replaced every day with a new one and the patient was instructed how to remove and insert the contact lens. After 5 days of admission, all patients were discharged and instructed to come for follow-up every week. The patients were followed up for 2 weeks after which medical treatment was stopped, with gradual withdrawal of topical steroids. After cessation of all drugs, the patients were continued on a weak topical steroid (fluorometholone; FML ${ }^{\circledR}$, Allergan Inc.) and lubricants to improve corneal healing and decrease the density of the corneal scar. After 6 weeks of follow-up, all patients were instructed to attend the outpatient clinic for suture removal under topical anesthesia (benoxinate hydrochloride $0.4 \%$; Benox ${ }^{\circledR}$, Epico Inc.) after topical antibiotic (Vigamox) installation four times daily for 3 days, After suture removal, all patients were kept on fluorometholone (FML) and lubricants until they completed 3 months of follow-up. After 3 months, each patient underwent assessment of visual function; postoperative refraction, manifest refractive spherical equivalent (MRSE), uncorrected visual acuity (UCVA), and best-corrected visual acuity (BCVA) were measured in both groups, the compared and statistically analyzed.

\section{Statistical analysis}

Statistical analysis of data was conducted using the chi-square test and $t$-test with the Statistical Package for the Social Sciences version 20 software (IBM Corporation, Armonk, NY, USA). The data are presented as the mean and standard deviation.

\section{Results}

Slit-lamp examination of patients in both groups revealed that the size of the corneal wounds was in the range of 3-10 mm long at different sites in the cornea: 17 cases were central (involving the central $8 \mathrm{~mm}$ ), 35 cases were mainly peripheral (outside the central $8 \mathrm{~mm}$ ), and eight cases involved both the central and peripheral areas of the cornea. The right eye was injured in 41 cases and the left eye in 19 cases. One case in the contact lens group had two separate corneal wounds, each of which reached the limbus (Figures 1, 2, 3, and 4). The mean patient age was $19.3 \pm 8.7(5-39)$ years in the contact lens group and $22.7 \pm 6.4(7-37)$ years in the non-contact lens group. The contact lens group included 24 male and six female patients, while the non-contact lens group included 17 male and 13 female patients.

In the contact lens group, postoperative refraction measurement showed a mean spherical error of $+0.3 \pm 2.36$ (range -1.75 to +3.5 ) $\mathrm{D}$ and a mean degree of astigmatism of $-1.7 \pm 2.93$ (range -4.5 to +3.25 ) D. Mean MRSE in the contact lens group was $-0.62 \pm 2.31$ (range -2.75 to +4.25 ) D. In the non-contact lens group, postoperative refraction measurement showed a mean spherical error of $+0.09 \pm 2.23$ (range -2.5 to +4.75 ) $\mathrm{D}$ and a mean degree of astigmatism of $+2.43 \pm 3.34$ (range -6 to +5.5 ) D. Mean MRSE in the noncontact lens group was $+1.28 \pm 2.33(5.25$ to +5.50$) \mathrm{D}$.

Visual acuity measurement using the decimal system revealed the following results. Postoperative UCVA in the contact lens group was 0.1 in three cases, 0.2 in eight, 

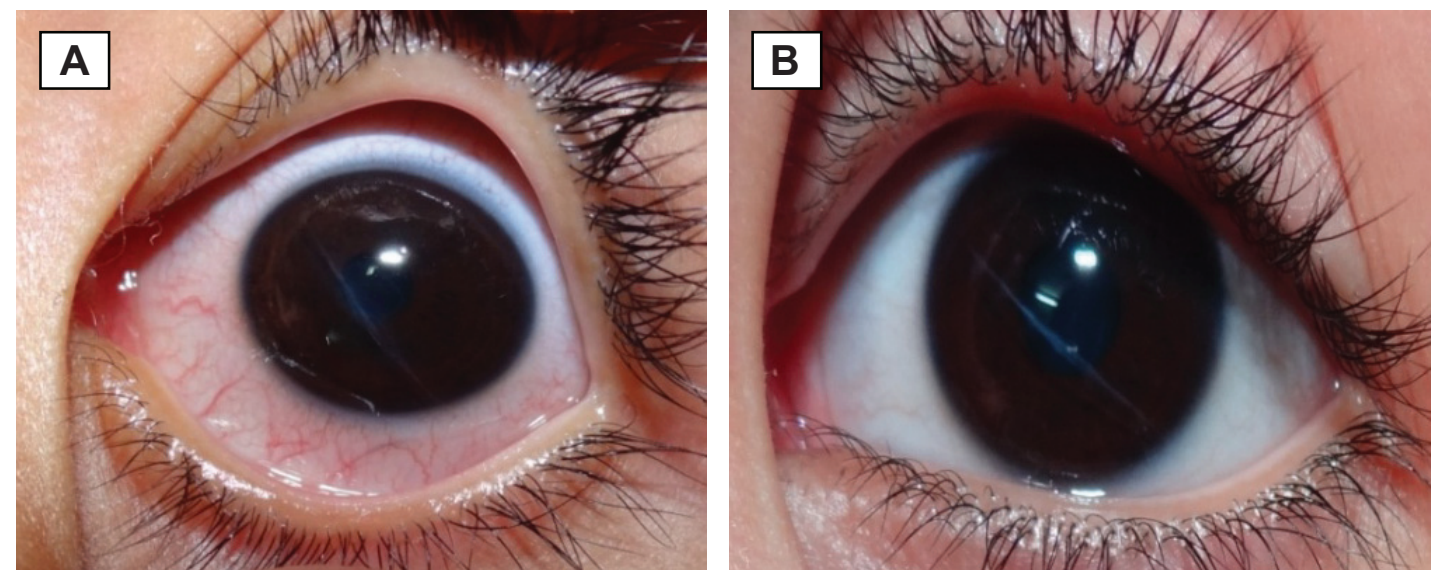

Figure I Photograph showing a full thickness corneal wound caused by a knife and involving the central $8 \mathrm{~mm}$ of the cornea (A) before and (B) after repair and contact lens fitting after 3 months of follow-up. The best-corrected visual acuity achieved was 0.7 .
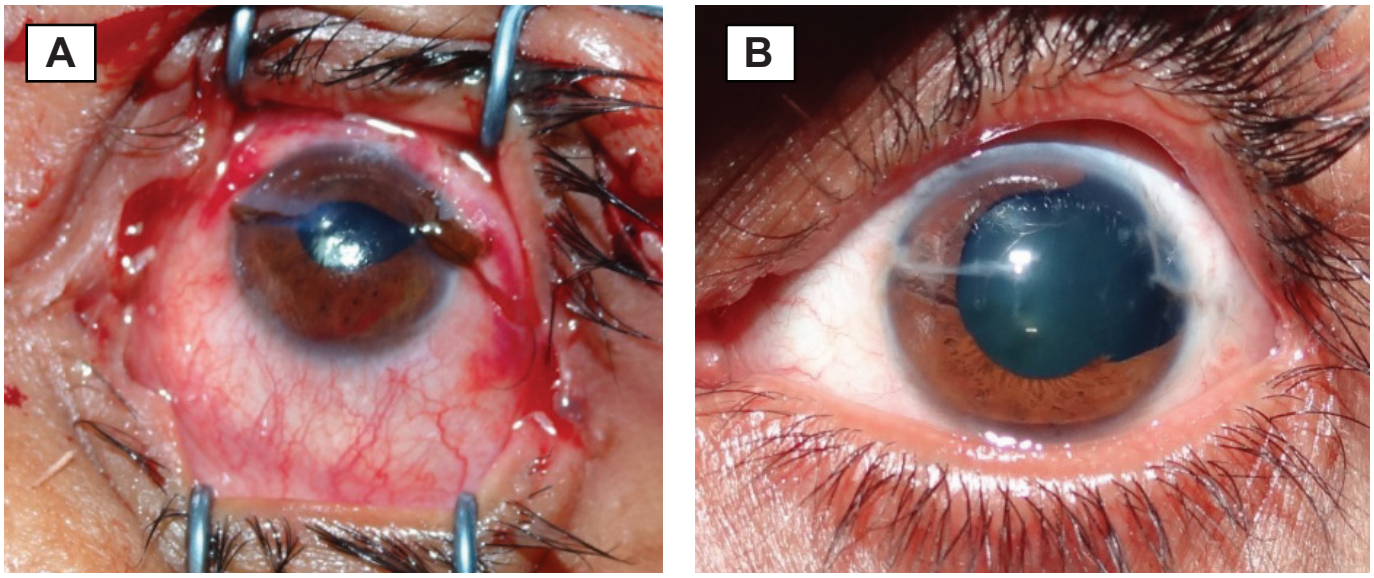

Figure 2 Photograph showing two full thickness corneal wounds caused by pieces of glass in a car accident and mainly involving the cornea outside its central $8 \mathrm{~mm}(\mathbf{A})$ before and (B) after repair and contact lens fitting after 3 months of follow-up. The best-corrected visual acuity achieved was 0.7 .
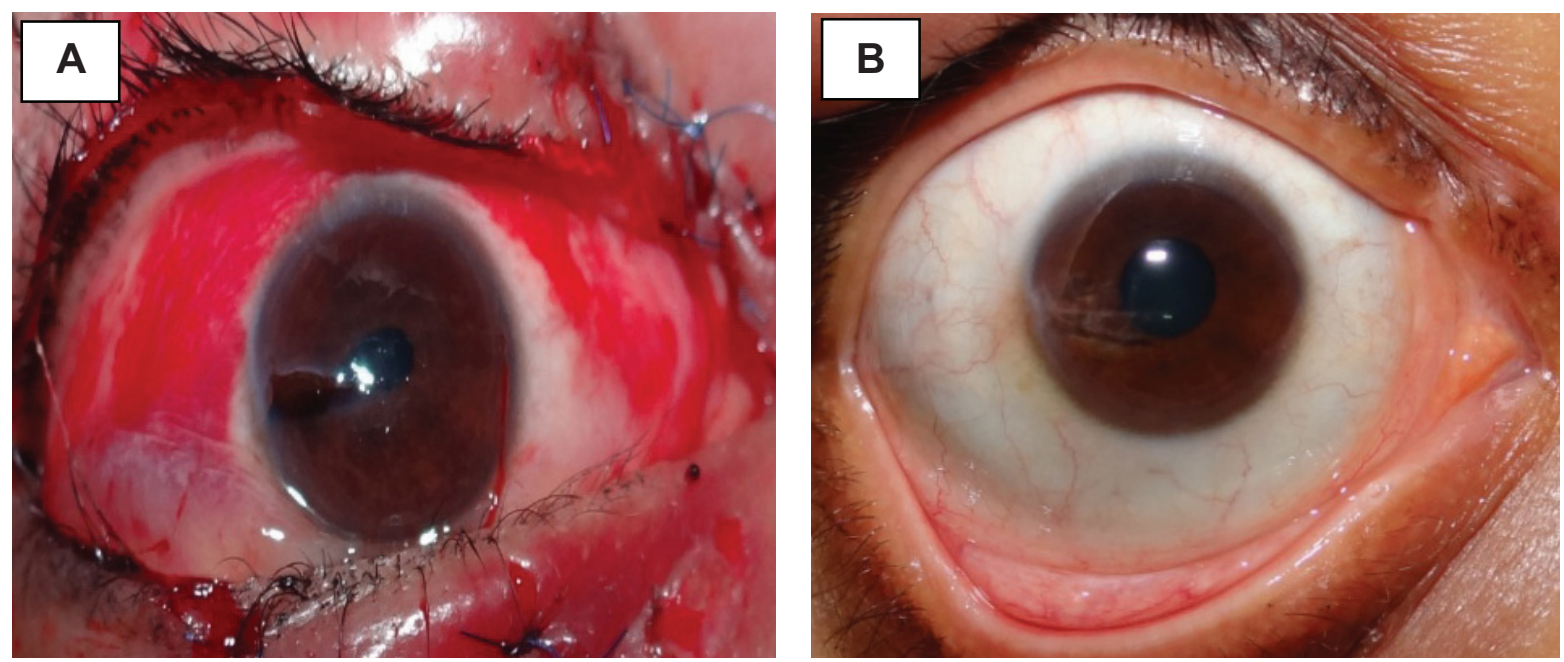

Figure 3 Photograph showing a full thickness corneal wound caused by a piece of glass in a car accident and involving the central and peripheral cornea (A) before and (B) after repair and contact lens fitting after 3 months of follow-up. The best-corrected visual acuity achieved was 0.7 . 

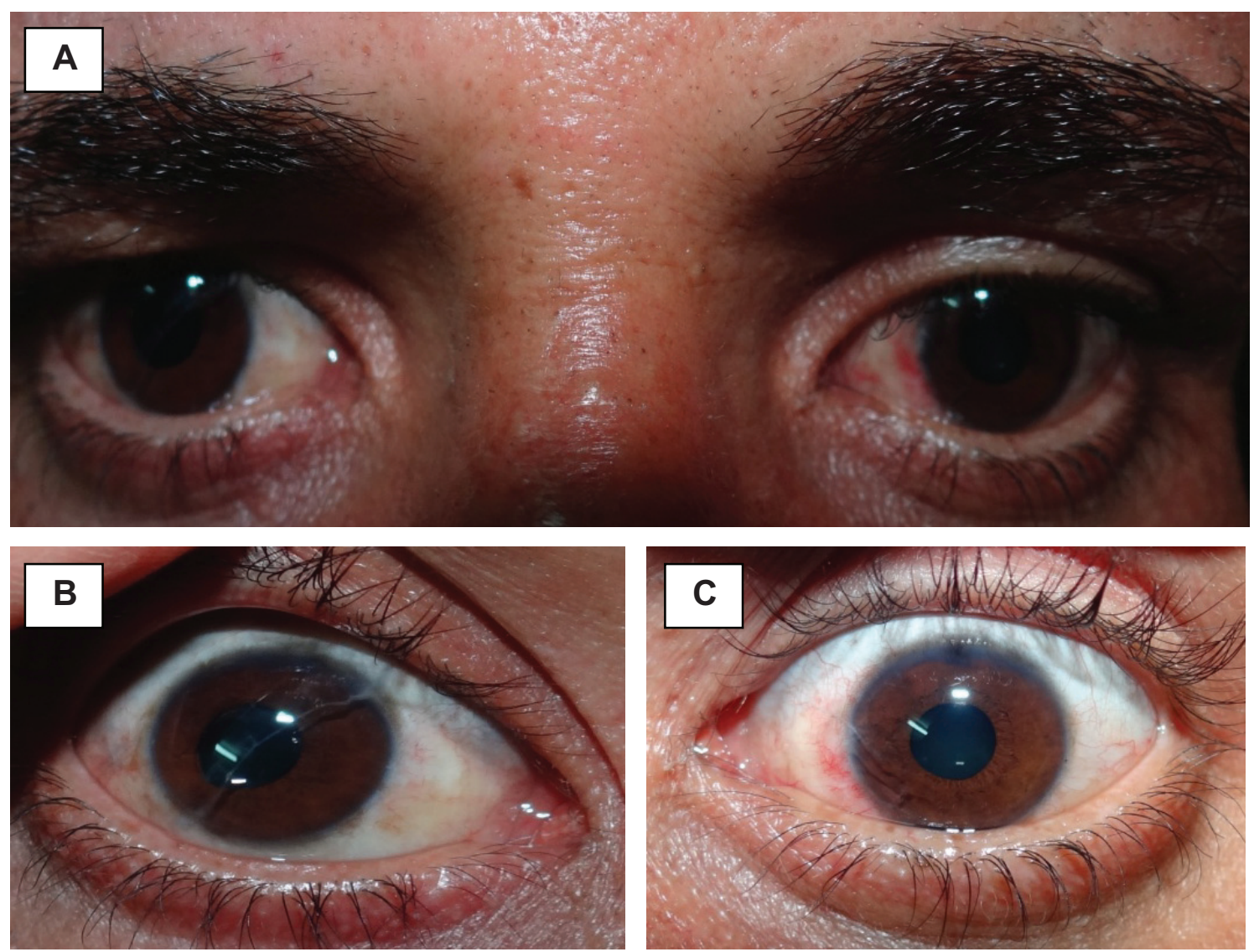

Figure 4 Photograph showing repaired bilateral full thickness corneal wound (A) caused by a piece of glass in a gas station explosion and involving the central and peripheral cornea in the right eye (B) and only the peripheral cornea in the left eye (C) after repair and contact lens fitting and 3 months of follow-up. The best-corrected visual acuity achieved was 0.5 in the right eye and 0.8 in the left eye.

0.3 in eight, 0.4 in seven, and 0.5 in four, and in the noncontact lens group was 0.1 in six cases, 0.2 in ten, 0.3 in seven, 0.4 in five, and 0.5 in two. Postoperative BCVA in the contact lens group was 0.5 in four cases, 0.6 in eight, 0.7 in eleven, and 0.8 in seven, and in the non-contact lens group was 0.4 in nine cases, 0.5 in four, 0.6 in eight, 0.7 in five, and 0.8 in four.

Comparing the visual acuity results between the two groups, 19 cases $(63 \%)$ achieved a UCVA $\geq 0.3$ in the contact lens group while only 14 cases $(47 \%)$ achieved a UCVA $\geq 0.3$ in the non-contact lens group $(P=0.018)$. In regards to the BCVA, the contact lens group included 26 cases $(87 \%)$ who achieved $\geq 0.6$ while only 17 cases $(57 \%)$ in the non-contact lens group achieved $\geq 0.6(P=0.012)$. See Table 1 and Figure 5.

\section{Discussion}

Management of traumatic corneal wounds represents one of challenges facing ophthalmologists all over the world. Surgical repair is the way adopted to manage this problem. In the USA, 3\% of patients attending the emergency department are suffering from different forms of ocular trauma. Careful examination and assessment are very important to prevent more ocular damage and maintain useful vision. ${ }^{8}$

When dealing with open globe injury, it is very important to rule out life-threatening injuries that may be associated. History-taking is crucial in order to detect the timing, mechanism, location of injury, and type of material involved; objects of an organic nature like wood have a great risk of infection, while objects of a metal nature may cause an intraocular reaction such as siderosis and chalchosis. ${ }^{8}$ After history-taking, a careful ocular examination

Table I Postoperative visual acuity results in both groups

\begin{tabular}{|c|c|c|c|c|}
\hline & \multicolumn{2}{|c|}{$\operatorname{UCVA}(\geq 0.3)$} & \multicolumn{2}{|c|}{$\operatorname{BCVA}(\geq 0.6)$} \\
\hline & n & $\%$ & $\mathbf{n}$ & $\%$ \\
\hline Contact lens & 19 & 63 & 26 & 87 \\
\hline Non-contact lens & 14 & 47 & 17 & 57 \\
\hline$\chi^{2}$ & \multicolumn{2}{|c|}{3.147} & \multicolumn{2}{|c|}{5.726} \\
\hline$P$-value & \multicolumn{2}{|c|}{$0.018^{*}$} & \multicolumn{2}{|c|}{$0.012 *$} \\
\hline
\end{tabular}

Note: *Statistically significant.

Abbreviations: BCVA, best-corrected visual acuity; UCVA, uncorrected visual acuity. 


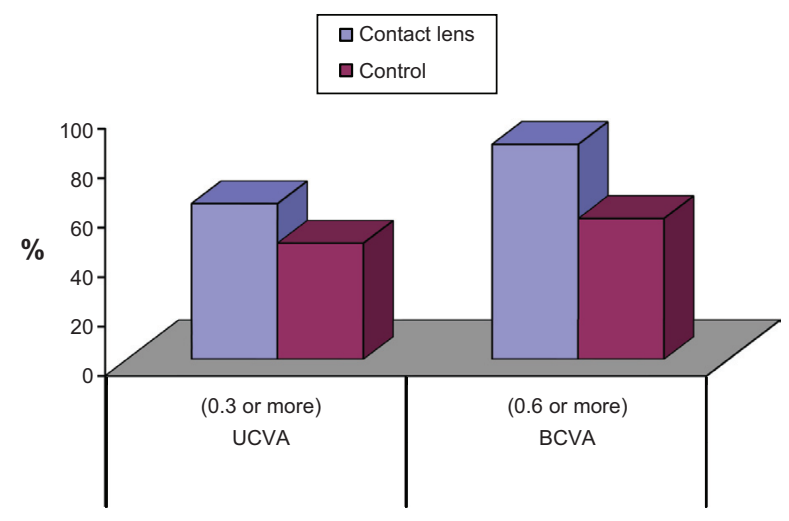

Figure 5 Postoperative visual acuity results in both groups.

Abbreviations: BCVA, best-corrected visual acuity; UCVA, uncorrected visual acuity

should be performed in a systematic way as to not to miss any injuries. ${ }^{3}$

Radiological examination and imaging techniques can provide valuable information about possible associated injuries, like orbital wall fractures and intraocular foreign bodies. ${ }^{9}$

Of the radiological imaging techniques, computed tomography provides the most valuable data, whereas plain X-ray and magnetic resonance imaging have a limited role. ${ }^{10,11}$

Ocular ultrasonography can provide valuable data about the extent of ocular damage, the presence of intraocular foreign bodies, and associated orbital injuries. One study reported that ocular ultrasound had a sensitivity of $100 \%$ and a specificity of $97.2 \%$ for identifying ocular pathology. ${ }^{12,13} \mathrm{In}$ cases of ocular trauma, many factors affect the final visual outcome, such as the extent of ocular damage, associated ocular and extraocular injuries, possible infection, availability of expert ophthalmologists, and the presence of a well equipped and qualified theater. In this study, every effort was made to follow the well known guidelines for management of such cases. Our theater at Tanta University Hospital is well qualified and equipped. We excluded cases of full thickness corneal wounds associated with other ocular or extraocular injuries. When corneal or intraocular infections occurred, these cases were also excluded. Repair was done by a well qualified expert ophthalmologist. Every effort was made to rule out the effect of other factors that may be associated with such cases and are known affect the process of repair, healing, and final visual outcome.

To the author's best knowledge, there are no reports or retrospective studies that had investigated the use of contact lenses in traumatic corneal wounds as an attempt to improve visual outcome after repair of the wound. The soft contact lens fitted over the repaired cornea was used as a template that reformed the shape of the cornea and decreased the deformity of the corneal surface responsible for the resulting degree of irregular astigmatism, and so visual outcome was improved.

The role of a therapeutic soft contact lens in such cases of traumatic full thickness corneal wounds is to return the corneal tissues to a more anatomical and functional state by keeping the edges of the wounds coapted and appositioned, thereby promoting wound healing and providing the mechanical support and protection needed during the process of healing. Using this strategy healing is much more rapid and successful, ending with a fine faint linear, so its effect in terms of the final visual outcome is less dramatic and good useful vision is be preserved.

In our study, the resulting mean spherical error was $+0.3 \pm 2.36$ (range -1.75 to +3.5 ) $\mathrm{D}$ and the mean degree of astigmatism was $-1.7 \pm 2.93$ (range $-4.5+3.25$ ) $\mathrm{D}$ in the contact lens group. Mean MRSE in the contact lens group was $0.62 \pm 2.31$ (range -2.75 to +4.25 ) $\mathrm{D}$. The results of postoperative refraction measurement in the non-contact lens group showed a resulting mean spherical error of $+0.09 \pm 2.23$ (range -2.5 to +4.75 ) $\mathrm{D}$ and a mean degree of astigmatism of $+2.43 \pm 3.34$ (range -6 to +5.5 ) D. Mean MRSE in the non-contact lens group was $+1.28 \pm 2.33$ (range $-5.25+5.5) \mathrm{D}$.

It is obvious that the ranges of resultant spherical error, astigmatism, and MRSE were smaller in the contact lens group, denoting better healing and an improved anatomical and functional state of the injured cornea after repair when using the soft contact lens as a template or bandage to maintain the structural integrity of the cornea.

In regards to the visual acuity results, UCVA $\geq 0.3$ was achieved in 19 cases (63\%) in the contact lens group and in only 14 cases $(47 \%)$ in the non-contact lens group. BCVA $\geq 0.6$ was achieved in 26 cases $(87 \%)$ in the contact lens group and in only 17 cases $(57 \%)$ in the non-contact lens group. When visual acuity results of both groups were compared using the chi-square test, a significant $P$-value of 0.018 was obtained for UCVA and of 0.012 for BCVA.

The visual acuity results showed that UCVA and BCVA were more improved in the contact lens group than in the noncontact lens group, indicating that the final visual outcome was much better in the former group. The goal of soft contact lens use to repair full thickness corneal wounds was achieved.

\section{Disclosure}

The author reports no conflicts of interest in this work. 


\section{References}

1. Rahman I, Maino A, Devadson D, et al. Open globe injuries: factors predictive of poor outcome. Eye. 2006;20:1336-1341.

2. Hatton MP, Thakkar MM, Ray S. Orbital and adnexal trauma associated with open globe injuries. Ophthalmol Plast Reconstr Surg. 2002;18: $458-461$.

3. Bord SP, Linden J. Trauma to the globe and orbit. Emerg Med Clin N Am. 2008;26:97-123.

4. Kreidl K, Kim D, Mansour S. Prevalence of significant intraocular sequelae in blunt ocular trauma. Am J Emerg Med. 2003;21:525-528.

5. Esmaeli B, Elner SG, Schork MA, Elner VM. Visual outcome and ocular survival after penetrating trauma. A clinicopathologic study. Ophthalmology. 1995;105:393-400.

6. Smith D, Wrenn K, Stack LB. The epidemiology and diagnosis of penetrating eye injuries. Acad Emerg Med. 2002;9:209-213.

7. Rubinstein MP. Applications of contact lens devices in the management of corneal disease. Eye. 2003;17:872-876.
8. Harlan JB, Pieramici DJ. Evaluation of patients with ocular trauma. Ophthalmol Clin North Am. 2002;15:153-161.

9. Lakits A, Prokesch R, Scholda C. Orbital helical computed tomography in the diagnosis and management of eye trauma. Ophthalmology. 1999;106:2330-2335.

10. Iinuma T, Hirota $Y$, Ishio K. Orbital wall fractures. Conventional views and CT. Rhinology. 1994;32:81-83.

11. Holmgren E, Dierks E, Homer L, et al. Facial computed tomography use in trauma patients who require a head computed tomogram. J Oral Maxillofac Surg. 2004;62:913-918.

12. Blaivas M, Theodoro D, Sierzenski P. A study of bedside ultrasonography in the emergency department. Acad Emerg Med. 2002;9: 791-799.

13. McIlrath ST, Blaivas M, Lyon M. Diagnosis of periorbital gas in ocular ultrasound after facial trauma. Am J Emerg Med. 2005;23:517-520.
Clinical Ophthalmology

\section{Publish your work in this journal}

Clinical Ophthalmology is an international, peer-reviewed journal covering all subspecialties within ophthalmology. Key topics include: Optometry; Visual science; Pharmacology and drug therapy in eye diseases; Basic Sciences; Primary and Secondary eye care; Patient Safety and Quality of Care Improvements. This journal is indexed on

\section{Dovepress}

PubMed Central and CAS, and is the official journal of The Society of Clinical Ophthalmology (SCO). The manuscript management system is completely online and includes a very quick and fair peer-review system, which is all easy to use. Visit http://www.dovepress.com/ testimonials.php to read real quotes from published authors. 